\title{
Intrauterine Depressed Skull Fracture
}

\author{
P. \\ Paul \\ Steinbok
}

British Columbia's Children's Hospital, Vancouver, B.C., Canada

Paul Steinbok, MB, British Columbia's Children's Hospital, 4480 Oak Street, Vancouver, BC V6H 3V4 (Canada)

Dear Sir,

I read with interest the report of 2 cases of intrauterine depressed skull fracture [1]. I must take exception to the statement by the authors that 'it appears that surgical therapy is the most appropriate method' of treatment. The authors have argued that 'localized pressure from the depressed region may cause cerebral function damage, a decrease in cerebral blood flow, and epilepti-genic foci' and they have cited as evidence for that a paper by Jennett et al. [2]. In fact, Jennett et al. showed that there was no difference in epilepsy in patients who had had depressed skull fractures either simple or compound elevated versus those who had not had surgical treatment. We have reported previously [3] that there was no difference in outcome between surgically and nonsurgically treated children with simple depressed skull fractures with respect to the occurrence of seizures, neurologic dysfunction, or cosmetic appearance. Since our original paper, we have continued to treat children with simple depressed skull fractures, especially in infancy and especially those at birth, without resorting to a surgical procedure. The bony contour in the newborns with depressed skull fractures invariably remodels to a normal situation and surgery can be avoided in these situations. The major indication for surgical elevation

of a simple depressed skull fracture in a child, in my opinion, is to prevent unacceptable cosmetic appearance in the long-term and this applies more to older children where cranial remodelling is not a prominent feature than to infants. I think that it is wrong to invoke a concern regarding brain dysfunction or epilepsy as an indication for surgical elevation of simple depressed skull fractures since there has never been any evidence to show that such a concern is justified.

References

Nakahara, T.; Sakoda, K.; Uozumi, T.; Takeda, T.; Ogorochi, T.; Ueda, K.; Ueda, M.; Sasaki, T.: Intrauterine depressed skull fracture: a report of two cases. Pediat. Neurosci. 75:121-124 (1989).

Jennett, B.; Miller, J.D.; Braakman, R.: Epilepsy after nonmissile depressed skull fracture. J. Neurosurg. 41:208-216 (1974).

Steinbok, P.; Martens, D.: Management of simple depressed skull fractures in children. J. Neurosurg. 66: 506-510 (1987). 